\title{
Prevalence of Obstructive Sleep Apnea in Type 2 Diabetes Mellitus
}

\section{Robert Ekka, J C Suri, Charanjit Singh, M K Sen, Anant Gupta}

\section{Introduction}

Obstructive Sleep Apnea (OSA) affects about 4\% of men and $2 \%$ of women of middle aged population, as defined by apnea-hypopnea index $(\mathrm{AHI})>5$ and daytime excessive sleepiness ${ }^{(1)}$. OSA is common in obese patients and also its prevalence increases with increasing body mass index (BMI). Whether OSA is caused by or results in central obesity is not fully understood. More recently, the National Cholesterol Education Programme (NCEP) Adult Panel - III (ATP-III) (2001) has identified a "Constellation of lipid and non lipid risk factors of metabolic origin", which is designated as "metabolic syndrome". This syndrome has been closely linked to insulin resistance. Type 2 Diabetes mellitus (T2DM) is a condition of impaired glucose tolerance and insulin resistance which also has a strong causal relationship with central obesity. OSA is also associated with insulin resistance, with higher level of OSA associated with greater insulin resistance independent of general obesity $^{(38,39) .}$ Due to reasons not yet clear, OSA may therefore be a particular problem in patients with T2DM. Central obesity is commonly seen in patients with insulin resistant T2DM. Probably, there is an aspect of central obesity with T2DM that contributes to OSA. A number of studies have demonstrated abnormal glucose tolerance and hyperinsulinemia in patients with OSA ${ }^{(2)}$.

\author{
Address for correspondence \\ Dr J C Suri \\ Professor \& Head of the Department of \\ Pulmonary, Critical Care \& Sleep Medicine, \\ Vardhman Mahavir Medical College \& Safdarjung \\ Hospital, New Delhi, email: jcsuri@rediffmail.com
}

The prevalence of T2DM is increasing rapidly; so is the prevalence of undiagnosed OSA in the diabetic population. This results into significant morbidity and a huge financial \& social burden. In India, it is estimated that 19.4 million individuals are affected by Diabetes mellitus, which is likely to go up to 57.2 million by the year 2025. The likely reasons include changing lifestyle, increased longevity and low birth weight. Data on the various aspects of the OSA-T2DM relationship, particularly from developing countries like ours, is scanty. With this in mind, a study was conducted to assess the prevalence of OSA in a small population of T2DM and further observe any correlations.

The aims and objectives of the study were as follows:

1. To study the prevalence of OSA in T2DM

2. To study the role of Diabetes mellitus as a risk factor for OSA

3. The role of OSA in glycemic control in patients with Diabetes mellitus.

\section{Material and Methods}

The study was conducted in the Department of Pulmonary, Critical Care and Sleep Medicine, Safdarjang Hospital \& Vardhman Mahavir Medical College, New Delhi. Three hundred and twentyfive patients of T2DM attending the Out Patients Department (Medicine \& Diabetes Clinic) of Safdarjang Hospital \& Vardhman Mahavir Medical College were randomly selected for the study. They were asked to fill the Berlin's Questionnaire for sleep apnea. Based on their response to this questionnaire, the patients were classified as either "high risk group" or "low risk group" for OSA. All such

Indian Journal of Sleep Medicine (IJSM), Vol. 5, No. 1, 2010 
patients underwent complete physical examination and overnight polysomnography. The patients were aged 3575 years. Patients with COPD, bronchial asthma, history of hospitalization in past six months and those on hormones causing hyperglycemia were excluded from the study. The diagnosis of DM was made according to American Diabetes Association criteria ${ }^{(3)}$ i.e. symptoms of DM plus casual plasma glucose $\geq 200 \mathrm{mg} / \mathrm{dL}$ or fasting glucose $\geq 126 \mathrm{mg} / \mathrm{dL}$ or two hour post-load glucose $\geq 200$ $\mathrm{mg} / \mathrm{dL}$ during oral glucose tolerance test. Routine laboratory investigation included hemogram, blood urea, serum creatinine, $\mathrm{HbA}_{1} \mathrm{c}$ estimation and fundus examination.

Level -1 Polysomnography was conducted in the sleep laboratory of the institution. It included electroencephalography, electro-oculography, chin electromyography, oro-nasal airflow (by nasal thermistors and nasal pressure transducer), rib cage and abdominal movements, arterial oxygen saturation (pulse oximetry), electrocardiography and body position. An Alice 5 Healthdyne Polysomnography system (Respironics, USA) was used. Sleep staging was performed using the criteria of Rechtshaffen and Kales. A trained physician validated all the sleep studies manually. Apnea was defined as cessation of airflow for $\geq 10$ seconds. Hypopnea was defined as an event lasting at least 10 seconds and characterized by $\geq 50 \%$ reduction in validated measure of breathing or a $50 \%$ or less reduction if associated with an oxygen desaturation of at least $3 \%$ or an arousal. Flow limitation was defined as any series of two or more breaths, lasting > 10 seconds, that have a flattened, nonsinusoidal appearance on the inspiratory nasal cannula flow signal and end sharply with a return to breaths with a sinusoidal shape. Respiratory Disturbance Index (RDI) was calculated as a sum of apneas, hypopneas and flow limitations. Desaturation was defined as a fall of $>3 \%$ in saturation from baseline following an obstructive event. The number of such episodes per hour was taken as desaturation index (DI). Arousal was defined as EEG alpha bursts exceeding 3 seconds during NREM sleep and bursts with accompanying chin muscle tone during REM. All non-respiratory arousals were eliminated. The number of arousals per hour was taken as Arousal Index (AI). Categorization of severity of OSA was done into three groups; mild (RDI=5-14), moderate (RDI=15-30) and severe $(\mathrm{RDI}>30)^{40}$. Anthropometric measurements (body mass index and neck circumference, waist-hip ratio) were also recorded for every patient.

\section{Statistical methods}

The observed data for various biochemical parameters were presented in terms of minimum, maximum and mean \pm standard deviation (SD) for a descriptive analysis. Further analysis of the data for categorical variables was done using Chi-square test. Logistic regression was applied for BMI adjustment. The level of statistical significance was taken as $\mathrm{P} \leq 0.05$. The data was analysed by using the SPSS statistical software, version 15.0 .

\section{Observations and Results}

Amongst the 325 patients recruited for the study, 85 patients were identified as falling in the risk group on the basis of response to Berlin Questionnaire. All the 85 patients were subjected to Polysomnography (PSG). After PSG, 79 patients were found to have significant sleep disordered breathing.

The prevalence of OSA in type $2 \mathrm{DM}$ was found to be 24.3\% (Males $28 \%$, females $19.9 \%$ )

Amongst the 325 patients of T2DM who were screened with Berlin Questionnaire,16.3\%belonged to the high risk group and $9.9 \%$ to the low risk group (Table-1)

Table 1: Risk Categorization based on Berlin Questionnaire

\begin{tabular}{|l|c|c|}
\hline Risk Group & Number & Percentage \\
\hline High risk & 53 & $16.3 \%$ \\
\hline Low risk & 32 & $9.9 \%$ \\
\hline No risk & 240 & $73.8 \%$ \\
\hline
\end{tabular}

Table 2: Total Prevalence of the cases

\begin{tabular}{|l|c|c|c|c|}
\hline & $\begin{array}{c}\text { Diabetics } \\
\text { with OSA }\end{array}$ & $\begin{array}{c}\text { Diabetics } \\
\text { without OSA }\end{array}$ & $\begin{array}{c}\text { Total } \\
\text { Diabetics }\end{array}$ & $\begin{array}{c}\text { Per- } \\
\text { centage }\end{array}$ \\
\hline Male & 49 & 125 & 174 & $28 \%$ \\
\hline Female & 30 & 121 & 151 & $19.9 \%$ \\
\hline Total & 79 & 246 & 325 & $24.3 \%$ \\
\hline
\end{tabular}

Majority of patient of the high-risk group had severe OSA and majority of the low-risk group patient had mild OSA

There was significant difference $(\mathrm{p}=0.007)$ in body mass index between patients of T2DM with OSA $(29.012 \pm$ 5.971). (Table 3) 
Table 3: Comparisons of characteristics between diabetics with OSA and diabetics without OSA

\begin{tabular}{|l|c|c|c|}
\hline Characteristics & Diabetic with OSA & Diabetic without OSA & P value \\
\hline Age (years) & $48.73 \pm 8.061$ & $47.7 \pm 10.085$ & 0.574 \\
\hline Heights $(\mathrm{cm})$ & $164.70 \pm 8.549$ & $165.09 \pm 8.887$ & 0.796 \\
\hline Weight $(\mathrm{Kg})$ & $78.25 \pm 12.220$ & $70.67 \pm 11.076$ & $<0.001$ \\
\hline Body mass index $\left(\mathrm{Kg} / \mathrm{m}^{2}\right)$ & $29.012_{ \pm 4.768}$ & $26.313_{ \pm} 5.971$ & 0.007 \\
\hline Neck circumference (inches) & $16.075 \pm 1.095$ & $15.772 \pm 8.646$ & 0.591 \\
\hline Waist circumference (inches) & $40.0 \pm 4.182$ & $39.41_{ \pm} 4.269$ & 0.412 \\
\hline Hip circumference (inches) & $41.03_{ \pm} 4.159$ & $40.31 \pm 4.047$ & 0.317 \\
\hline Waist/hip ratio & $09698_{ \pm} 0.074$ & $0.9701_{ \pm} 0.0448$ & 0.971 \\
\hline Fasting plasma glucose $(\mathrm{mg} / \mathrm{dl})$ & $123.65 \pm 19.543$ & $114.12 \pm 19.082$ & 0.006 \\
\hline PPP*Glucose $(\mathrm{mg} / \mathrm{dl})$ & $194 \pm 37.552$ & $181.67 \pm 36.593$ & 0.058 \\
\hline Blood urea $(\mathrm{mg} / \mathrm{dl})$ & $27.63_{ \pm} 8.270$ & $26.23 \pm 7.716$ & 0.323 \\
\hline Serum creatinine $(\mathrm{mg} / \mathrm{dl})$ & $0.890_{ \pm} 0.2158$ & $0.871 \pm 0.143$ & 0.588 \\
\hline Haemoglobin $(\mathrm{gm} / \mathrm{dl})$ & $14.060_{ \pm} 0.9948$ & $13.095 \pm 1.551$ & $<0.001$ \\
\hline Platelet $(\mathrm{lakhs} / \mathrm{cu} . \mathrm{mm})$ & $2.517_{ \pm} 0.621$ & $2.627 \pm 0.640$ & 0.304 \\
\hline
\end{tabular}

*PPP Glucose=post-prandial plasma glucose

There was significant difference in BMI neck circumference and waist circumference between the high- risk \& low-risk groups of patients with T2DM with OSA (Table 4)

Table 4: Comparisons of characteristics between high and low risk group

\begin{tabular}{|c|c|c|c|}
\hline Characteristics & "Low risk" group & "High risk" group & $P$ value \\
\hline Age (years) & $48.0 \pm 7.585$ & $49.12 \pm 8.425$ & 0.673 \\
\hline Height $(\mathrm{cm})$ & $167.93 \pm 7.426$ & $162.96 \pm 8.738$ & 0.068 \\
\hline Weight (Kg) & $72.57 \pm 8.582$ & $81.31 \pm 12.917$ & 0.015 \\
\hline Body mass index $\left(\mathrm{kg} / \mathrm{m}^{2}\right)$ & $25.70_{ \pm} 1.964$ & $30.664 \pm 4.918$ & $<0.001$ \\
\hline Neck circumference (inches) & $15.57 \pm 0.385$ & $16.346 \pm 1.2551$ & 0.007 \\
\hline Waist circumference (inches) & $37.21 \pm 1.847$ & $41.40 \pm 4.338$ & $<0.001$ \\
\hline Hip circumference (inches) & $38.68 \pm 2.109$ & $42.29 \pm 4.464$ & 0.001 \\
\hline Waist/hip ratio & $0.960 \pm 0.0161$ & $0.9750_{ \pm} 0.0912$ & 0.425 \\
\hline Fasting plasma glucose $(\mathrm{mg} / \mathrm{dl})$ & $115.43 \pm 14.872$ & $128.08 \pm 20.556$ & 0.032 \\
\hline PPP* Glucose (mg/dl) & $179 \pm 19.010$ & $202.08 \pm 42.598$ & 0.063 \\
\hline Blood urea $(\mathrm{mg} / \mathrm{dl})$ & $26.43 \pm 4.586$ & $28.27 \pm 9.722$ & 0.422 \\
\hline Serum creatinine $(\mathrm{mg} / \mathrm{dl})$ & $0.807 \pm 0.0616$ & $0.935 \pm 0.254$ & 0.021 \\
\hline Haemoglobin $(\mathrm{gm} / \mathrm{dl})$ & $13.65 \pm 0.9557$ & $14.227 \pm 0.882$ & 0.055 \\
\hline Platelet (lakhs/cu.mm) & $2.41 \pm 0.622$ & $2.57 \pm 0.626$ & 0.471 \\
\hline Total Cholesterol (mg/dl) & $193.21 \pm 67.331$ & $176.88 \pm 36.426$ & 0.323 \\
\hline Triglyceride $(\mathrm{mg} / \mathrm{dl})$ & $130.14 \pm 30.417$ & $136.88 \pm 50.339$ & 0.601 \\
\hline $\mathrm{LDL}^{* *}(\mathrm{mg} / \mathrm{dl})$ & $88.29 \pm 21.098$ & $113.97 \pm 32.672$ & 0.005 \\
\hline $\mathrm{HDL}^{* * *}(\mathrm{mg} / \mathrm{dl})$ & $44.57 \pm 6.802$ & $41.75 \pm 5.602$ & 0.198 \\
\hline
\end{tabular}

${ }^{*}$ Post prandial plasma glucose, ${ }^{* *}$ Low density Lipoprotein, ${ }^{* * *}$ High density Lipoprotein 
There was significant difference in arousal index (AI), desaturation index (DI), minimum oxygen saturation $\left(\mathrm{O}_{2}\right.$ sat ${ }_{\text {min }}$ ) and respiratory disturbance index (RDI) between the high-risk \& low-risk groups of patients of T2DM with OSA. A positive and significant correlation was found between BMI and various sleep parameters like RDI, DI and $\mathrm{O}_{2}$ sat ${ }_{\text {min }}$. (Table 5 and diagram 1)

Table 5: Correlation between BMI and various sleep parameters

BMI correlates with Sleep parameters

\begin{tabular}{|l|c|c|}
\hline & $\mathbf{r}$ & pvalue \\
\hline RDI & .512 & $0.001^{*}$ \\
\hline Arousal Index & .220 & 0.172 \\
\hline Desaturation Index & .440 & $0.005^{*}$ \\
\hline Min O2 sat & -.384 & $0.014^{*}$ \\
\hline
\end{tabular}

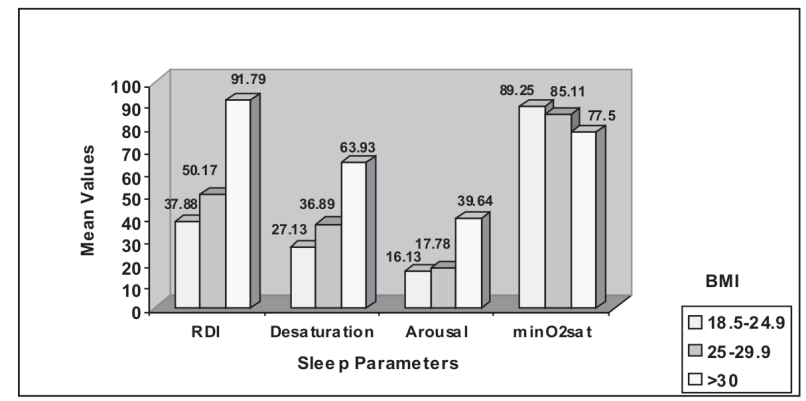

Diagram 1: Mean values of various sleep parameters amongst range of BMI values

A partial correlation was also observed between Diabetes and sleep parameters, after controlling (elimination of the influence) BMI. (Table 6)

There was a positive and significant correlation between $\mathrm{HbA}_{1} \mathrm{c}$ and various sleep parameters like RDI, DI and $\mathrm{O}_{2}$ sat $_{\text {min }}$. (Table 7 and the diagrams 2-4)

Table 6: Partial correlation between

Diabetes and Sleep parameters(controlled For BMI)

\begin{tabular}{|l|c|c|c|c|}
\hline & RDI & $\begin{array}{c}\text { Arousal } \\
\text { Index }\end{array}$ & $\begin{array}{c}\text { Desaturation } \\
\text { Index }\end{array}$ & $\begin{array}{c}\text { Min } \\
\text { O2 sat }\end{array}$ \\
\hline FBS & 0.394 & 0.317 & 0.408 & -0.237 \\
\hline & $\mathrm{p}=0.013^{*}$ & $\mathrm{p}=0.049$ & $\mathrm{p}=0.01^{*}$ & $\mathrm{p}=0.146$ \\
\hline PPBS & 0.366 & 0.276 & 0.366 & -0.153 \\
\hline & $\mathrm{p}=0.022^{*}$ & $\mathrm{p}=0.089$ & $\mathrm{p}=0.022^{*}$ & $\mathrm{p}=0.353$ \\
\hline $\mathrm{HbA}_{1} \mathrm{c}$ & 0.68 & 0.227 & 0.666 & -0.436 \\
\hline & $\mathrm{p}<.001^{*}$ & $\mathrm{p}=0.164$ & $\mathrm{p}<.001^{*}$ & $\mathrm{p}=0.006^{*}$ \\
\hline
\end{tabular}

Indian Journal of Sleep Medicine (IJSM), Vol. 5, No. 1, 2010
Table 7:

NA

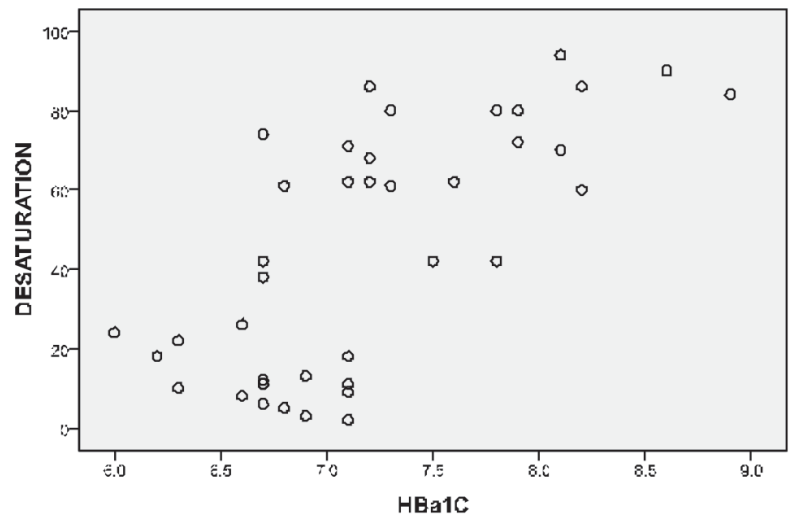

Diagram 2: Correlation between $\mathrm{KDI}$ and $\mathrm{HbA}_{1} \mathrm{c} \quad \mathrm{HbA}_{1} \mathrm{c}$

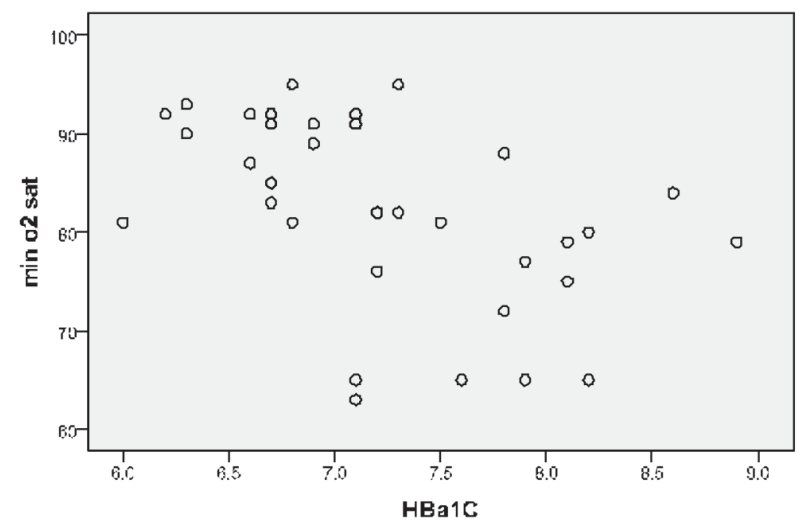

Diagram 3: Correlation between desaturation and $\mathrm{HbA}_{1} \mathrm{c} \mathrm{HbA}_{1} \mathrm{c}$

\section{NA}

Diagram 4: Correlation between $\min \mathrm{O}_{2}$ sat and $\mathrm{HbA}_{1} \mathrm{c}$ 


\section{Regression analysis}

Regression analysis of the observations also shows that severity of OSA depends on both BMI and $\mathrm{HbA}_{1}$ c. So the regression equation would be:

$\mathrm{RDI}=$ Constant $+2.849 \mathrm{BMI}-0.008 \mathrm{FBS}+0.058 \mathrm{PPBS}+36.757 \mathrm{HbA}_{1} \mathrm{c}$

Therefore in a given patient with Diabetes and clinically suspected OSA, whose BMI, Blood sugar values (fasting [FBS] and post-prandial [PBS]) and $\mathrm{HbA}_{1} \mathrm{c}$ are known, the severity of OSA (RDI) can be predicted by applying the above formula.

It has been estimated that BMI alone explains only $26.2 \%$ of variation in RDI. The contribution of Diabetes related parameters is over $40 \%$ in explaining the variation in RDI. Importantly $\mathrm{HbA}_{1} \mathrm{c}$ alone explains $21.9 \%$ of variation in RDI.

\section{Discussion}

Type 2 diabetes mellitus (T2DM) is a major public health burden. Many patients with T2DM also have OSA ${ }^{(4-6)}$. There is ample evidence that OSA is a significant risk factor for cardiovascular disease and mortality ${ }^{(7-10)}$. OSA is also an independent risk factor for development of T2DM ${ }^{(11)}$. The present study was undertaken in order to determine the prevalence of OSA in T2DM, to study the role of Diabetes as a risk factor for OSA and also to study the role of OSA in glycemic control of patients with Diabetes mellitus. In another study that included 330 consecutive adults with T2DM referred to a diabetes clinic, the overall prevalence rate of OSA was found to be $36 \%$ ( $49 \%$ in males and $21 \%$ in females) when an AHI cutoff value of 15 events / hour was taken while using a single channel recording device that measured breathing events from a nasal cannula airflow signal. ${ }^{(37)}$

Out of 325 patients of T2DM who were screened, 85 were identified to fall in the risk group; 32 in "low" risk and 53 in "high" risk groups respectively. The overall prevalence of OSA in T2DM was observed to be $24.3 \%$. The prevalence of OSA among patients with T2DM has been reported to vary in different studies, depending on subset of patients selected for the particular study. In a study from USA, of obese patients with T2DM, the prevalence of OSA was found to be $86 \% \%^{(5)}$. In a recent study, the prevalence of OSA in 60 consecutive patients with T2DM was found to be $77 \%{ }^{(12)}$. Another large study of 306 obese patients with diabetes reported a prevalence of OSA as $86 \%{ }^{(5)}$.
The Sleep Heart Health Study, which included older individuals, found the prevalence of OSA in T2DM as $58 \%{ }^{(4)}$. In a polysomnography based study of 1008 consecutive multi-ethnic patients, the prevalence of T2DM was $30.1 \%$ in the group with OSA compared to $18.6 \%$ in those without OSA ${ }^{(13)}$. Moderately severe sleep apnea was a significant risk factor for incident diabetes in an Australian population based cohort of 399 participants ${ }^{(14)}$. The prevalence of diabetes mellitus in Japanese OSAS patients were found to be higher than that of the control group $(25.9 \%$ vs $8.2 \% \mathrm{p}<0.001)$ and $62.4 \%$ patients received a new diagnosis of impaired glucose or diabetes mellitus ${ }^{(15)}$.

Sleep disordered breathing and sleep apnea are conditions frequently associated with co-morbidity including obesity, diabetes, hypertension, insulin resistance (metabolic syndrome) and cardiovascular disease. The alteration in circulating endothelial progenitor cells found in respiratory disease, the metabolic syndrome and cardiovascular disease reflect a common condition of endothelial dysfunction ${ }^{(16)}$. It has also been suggested that the metabolic syndrome be termed as "syndrome Z" (17.18).

In the present study, the prevalence of OSA was higher in T2DM than in normal general population; $28 \%$ vs $4 \%$ in males, and $19.9 \%$ vs. $2 \%$ in females. In another study based on questionnaires, that included male subjects exclusively, the prevalence of OSA in T2DM was found to be $23 \%{ }^{(19)}$. It has been suggested that various components of OSA like intermittent hypoxic, elevated sympathetic nervous activity, sleep fragmentation and low amounts of slow wave sleep and cumulative sleep loss have adverse effects on glucose tolerance ${ }^{(12,20,21,25,26)}$. Consistent with a recent study ${ }^{(12,23,24)}$, the present study also found a predominance of obstructive events rather than central events. This is a contrast to findings from Sleep Heart Health Study ${ }^{(4)}$ in which self-reported diabetes was associated with a significant rise in periodic breathing.

The present study observed a higher prevalence of OSA amongst diabetic individuals than in normal subjects. One probable explanation for this finding is the common occurrence of obesity amongst diabetics. It is well known that obesity predisposes to OSA; the frequent occurrence of obesity amongst diabetics can therefore predispose this subset of population to OSA. ${ }^{(18)}$.

In the present study, a significant difference was also found between the neck circumference, waist

Indian Journal of Sleep Medicine (IJSM), Vol. 5, No. 1, 2010 
circumference and BMI of "high risk" group of patients (16.346 inches) and "low risk group (15-57 inches). The abdominal deposition of fat has a more robust association with insulin resistance than peripheral distribution of fat ${ }^{(27,18)}$. BMI was found to be significantly different between diabetics with OSA and diabetics without OSA $(\mathrm{p}<0.007)$. However difference in neck circumference, waist $\&$ hip circumferences as well as waist-hip ratio was not significantly different between diabetics with OSA \& those without OSA. A positive correlation was also found between RDI and neck circumference $(\mathrm{r}=0.482)$, waist circumference $(\mathrm{r}=0.568)$, waist-hip ratio $(\mathrm{r}=0.369)$ and BMI $(\mathrm{r}=0.502)$. We also observed a positive and significant correlation between BMI and various sleep parameters like RDI, DI and $\mathrm{O}_{2} \mathrm{Sat}_{\min }$. (Table 5 \& Diagram 1).

It may also be added that diabetes can occur even without obesity. The higher prevalence of OSA amongst nonobese diabetics also warrants an explanation. It may be recalled that hyper-insulinemia is a common finding amongst diabetics. OSA has been observed to be more prevalent amongst other hyperinsulinemic states e.g. polycystic ovarian disease (PCOD). By the same analogy, the frequent occurrence of OSA among non-obese diabetics may also be attributed to the presence of hyperinsulinemia in these patients. Regression analysis in the present study also indicates that BMI alone explains only $26.2 \%$ of the severity of OSA ( ie variation in $\mathrm{RD}$ ); the contribution of diabetes related parameters is over $40 \%$.

\section{$\mathrm{HbA}_{1} \mathrm{c}$ and OSA}

The present study showed a significant correlation between $\mathrm{HbA}_{1} \mathrm{c}$ and RDI $(\mathrm{p}<0.001)$. Studies have, however, shown that, in normal subjects, short term sleep restriction (4h/night for six nights) results in worsening glucose tolerance, increased evening levels of cortisol, and heightened sympathetic activity ${ }^{(41)}$. Acute sleep deprivation can also dampen growth hormone secretion, modulate neuroendocrine control of appetite, and elicit an inflammatory response, thus unfavorably influencing glucose and insulin homeostasis ${ }^{(42)}$. Thus, hypoxia and sleep loss can independently contribute to disorders of glucose metabolism and thus may be vital in the putative pathway between sleep apnea and altered glucose metabolism. Another recent study has also shown significant associations between OSA severity and $\mathrm{HbA}_{1} \mathrm{c}$ $(\mathrm{p}=0.007$ and $\mathrm{p}=0.013$ for total AHI and REM AHI, respectively) ${ }^{12}$. These associations were stronger when a cut-off value for desaturation was taken as 3\% than when it was taken as $4 \%$. In another study involving a multi-ethic population, the mean $\mathrm{HbA}_{1} \mathrm{c}$ was higher in T2DM with OSA than in T2DM without OSA (6.8 versus 6.5) ${ }^{(13)}$. A study of 25 obese patients with diabetes showed improvements in $\mathrm{HbA}_{1} \mathrm{c}$ levels and post-prandial glucose levels after 3 months of CPAP use ${ }^{(28)}$.

The present study also shows a positive and significant correlation between $\mathrm{HbA}_{1} \mathrm{c}$ and various sleep parameters like RDI, DI, and O2sat ${ }_{\text {min }}$. It may be inferred from these findings that poor sleep may lead to worsening of diabetes control, possibly due to release of sympathomimetic amines and other factors enumerated earlier. It may also be probable that poor diabetes control can lead to worsening sleep parameters in OSA. This issue may require being further looked into by studies in future.

\section{Duration of Diabetes and OSA}

A significant correlation was found in this study, between the duration of diabetes and severity of OSA $(\mathrm{r}=0.654)$. There is scanty data in literature regarding this relationship.

\section{OSA and serum LDL cholesterol}

Higher level of LDL cholesterol were observed in "high" risk OSA group as compared to "low" risk group $(\mathrm{p}=0.005)$. This is similar to observations made in other studies ${ }^{(29,30)}$.

\section{OSA and fasting plasma glucose}

The fasting plasma glucose was significantly higher in the "high" risk OSA group than "low" risk group of T2DM patients $(\mathrm{p}=0.032)$. The severity of OSA, however, correlated significantly with fasting plasma glucose levels $(\mathrm{p}=0.013)$. In a study involving Japanese patients, a rising trend in fasting plasma glucose with increasing severity of OSA was reported ${ }^{(15)}$. From these findings it can be assumed that the presence of significant OSA in diabetic patients can result in poor glycemic control.

\section{OSA \& post-prandial plasma glucose}

This study has shown that the proportion of subjects with raised post-prandial plasma glucose was slightly 
higher, in "high" risk for OSA group that that of "low" risk for OSA group of patients with T2DM. Similar trends have also been seen in other studies ${ }^{(15,18)}$. OSA has been reported to have the strongest association with insulin resistance, glucose intolerance T2DM and the metabolic syndrome ${ }^{(31)}$.

Although OSA is associated with increased insulin resistance, studies of continuous positive airway pressure (CPAP) have shown varying effects on glycemic control. Sleeping glucose levels have been shown to decrease and are more stable after patients with T2DM and OSA are treated with CPAP ${ }^{(32,33)}$. Diabetic neuropathy and metabolic syndrome parameters correlate with the presence and severity of OSA ${ }^{(34,36)}$. Among patients with severe sleep apnea and no pre-existing diabetes, regular CPAP use was associated with an attenuation of the risk of diabetes ${ }^{(35)}$. Adult nonobese diabetics with autonomic neuropathy, independent of the severity of their dysautonomy, have been shown to have obstructive sleep apnea/hypopnea with a frequency of $>30 \%$. ${ }^{(24)}$

\section{Conclusion}

This study found a higher prevalence of OSA in patients of T2DM as compared to the general population. There may be an aspect of central obesity in T2DM which contributes to OSA as reflected in BMI and neck circumference, which was also found to be higher in the diabetic population than in general population. An increased level of $\mathrm{HbA}_{1} \mathrm{c}$ was found to be associated with increased severity of OSA. HbA1c alone was found to contribute to about $21.9 \%$ variation in $\mathrm{RDI}$.

Diabetes mellitus is a common clinical problem. OSA is nearly five times more common amongst diabetics than in non-diabetic subjects. The former can lead to worsening of the latter condition and vice-versa. Both clinical entities are associated with significant morbidity and mortality. Clinicians who manage patients of T2DM must, therefore, routinely enquire about symptoms of sleep-disordered breathing in them. Some limitations of the present study include the lack of BMI-matched groups (logistic and partial regression analysis was used to overcome this limitation) and the small sample size of diabetic patients. Further research should focus on interaction of OSA, obesity, measurements of insulin resistance and endothelial dysfunction and genetic determinants as for cardiovascular disease and benefits of CPAP on glycemic control.

\section{References}

1. Young $T$, Palta $M$, Dempsey J etal. The occurrence of sleep disordered breathing among middle-aged adults. N Engl J Med 1993; 328(17):1230-1235.

2. Reaven GM. Role of insulin resistance in human disease. Diabetes 1988; 37:1595-1607.

3. Powers AL. Diabetes Mellitus In: Harrison's Principles of Internal medicine. Fanci AS, Branwald E, Kasper DL (eds). $17^{\text {th }}$ edition. New York, McGraw Hill Medical 2008; 22752304 .

4. Resnick HE, Redline S, Shahar E, Gilpin A, Newman A, Walter R, Ewy GA, Howard BV, Punjabi NM. Diabetes and sleep disturbances; findings from the Sleep Heart Health Study. Diabetes Care 2003; 26:702-709.

5. Foster GD, Sanders MH, Millman R, Zammit G, etal. Obstructive sleep apnea among obese patients with type 2 diabetes. Diabetes Care 2009; 32:1017-1019.

6. Einhorn D, Stewart DA, Erman MK, Gordon $\mathrm{N}$ et al. Prevalence of sleep apnea in a population of adults with type 2 diabetes mellitus. Endocr Pract 2007; 13:355-362.

7. Somer S VK, White DP, Amin R et al. Sleep apnea and Cardiovascular disease: an American Heart Association/ American College of Cardiology Foundation Scientific Statement from American Heart Association Council for High Blood Pressure Research Professional Education Committee, Council of Clinical Cardiology, Stroke Council, and Council on Cardiovascular Nursing. J Am Coll Cardiol 2008; 52:686-717.

8. Yaggi HK, Concato J, Kernan Wai et al. Obstructive sleep apnea as a risk factor for stroke and death. N Engl J Med 2005; 353:2034-2041.

9. Young T, Finn L, Pepparel PE et al. Sleep disordered breathing and mortality: eighteen-year follow up of the Wisconsin Sleep Cohort. Sleep 2008; 31:14071-1078.

10. Bradley TD, Floras JS. Obstructive sleep and its cardiovascular consequences. Lancet 2009; 373:82-93.

11. Flegal KM, Caroll MD, Ogden CL and Johnson CL. Prevalence and trends in obesity among US adults. JAMA. 1999;288:1723-1727.

12. Aronsohn RS, Whitmore H, Van Cauter E, Tasali E. Impact of untreated obstructive sleep apnea on glucose control in Type 2 Diabetes. Am J Respir Crit Care Med 2010; 181:507-513.

13. Mahmood K, Akhter N, Eldeirawi K et al. Prevalence of type 2 diabetes in patients with obstructive sleep apnea in a multi-ethnic sample. J Clin Sleep Med 2009; 5(3):215221.

14. Marshall NS, Wong KKH, Phillips CL et al. Is sleep apnea an independent risk factor for prevalent and incident diabetes I the Busselton Health Study? J Clin Sleep Med 2009; 5(1):15-20.

15. Otake K, Sasanabe $R$, Hasegawa $R$ et al. Glucose intolerance in Japanese patients with obstructive sleep apnea. Inte Med 2009; 48:1863-1868.

Indian Journal of Sleep Medicine (IJSM), Vol. 5, No. 1, 2010 
16. Tiengo A, Fadini GP, Avogiro A. The metabolic syndrome, diabetes and lung dysfunction. Diabetes and Metabolism 2008; 34:447-454.

17. Wilcox I, McNamara SG, Collins FL et al. "Syndrome Z" the interaction of sleep apnea, Vascular risk factors and heart disease. Thorax 1998; 53(Suppl 3):S25-S28.7.

18. Kostoglou-Athanassiou I, Athanassiou P. Metabolic syndrome and sleep apnea. Hippokratia 2008; 12(2):81 86.

19. West SD, Nicoll DJ, Stradling JR. Prevalence of obstructive sleep apnea in men with type 2 diabetes mellitus. Thorax 2006; 61:945 -950.

20. Polotsky VY, Li J, Punjabi NM, Rubin AE et al. Intermittent hypoxia increases insulin resistance in generically obese mice. J Physiol 2003; 552:253-264.

21. Tasali E, Leproult R, Ehrmann DA, etal. Slow wave sleep and the risk of type 2 diabetes in humans. Proc Natl Acad Sci USA 2008;105:1044-1049.

22. Spiegel K, Knutson K, Leproult R et al. Sleep loss: a novel risk factors for insulin resistance and type 2 diabetes. J Appl Physiol 2005; 99:2008-2019.

23. Bottini P, Redolfi S, Dottorini ML et al. Autonomic neuropathy increases the risk of obstructive sleep apnea in obese diabetes. Respiration 2008; 75:265-271.

24. Bottini P, Dottorini ML, Cristina Cardons $M$, Casucci $G$ et al. Sleep-disordered breathing in non obese diabetes subjects with autonomic neuropathy. Eur Respir J 2003. 22:654-660.

25. Zizi F, Jean-Louis G, Brown CD, Ogedegbe G, Boutin-Foster C, McFarlance SI. Sleep duration and the risk of diabetes mellitus: epidemiologic evidence and pathophysiologic insights. Curr Diab Rep 2010; 10(1):43-47.

26. Muraki I, Tanigawa T, Yamagishi K, Sakurai S, Ohira T et al. Nocturnal intermittent hypoxia and the development of type 2 diabetes: the Circulatory Risk in communities study (CIRCS). Diabetologica 2010; 53(3):481-488.

27. Koopman RJ, Swafford SJ, Beard MN, Meadows SE. Obesity and metabolic disease. Prim Care Clin office Pract 2009. 36:257-270.

28. Babu AR, Herdegen J, Fogelfeld L, Shott S, Mazzone T. Type 2 diabetes, glycemic control and continuous positive airway pressure in obstructive sleep apnea. Arch Intern Med 2005; 165:447-452.

29. Coughlin SR, Manidsley L, Murgaza JA et al. Obstructive sleep apnea is independently associated with an increased prevalence of metabolic syndrome. Eur Heart J 2004; 25:735-741.
30. Peted N, Kassirer M, Shitrit D et al. The association of OSA with insulin resistance, inflammation and metabolic syndrome. Respiratory Med 2007; 101:1696-1701.

31. Punjabi NM, Brown WD, Erman M, Slade G, Neubauer D, Ferri R, Hong SC, Partinen M, Hines M, Weitz M. Do sleep disorders are associated treatments impact glucose metabolism? Drugs 2009; 69:2:13-27.

32. Dawson A. CPAP therapy of obstructive sleep apnea in type 2 diabetes improves glycemic control during sleep. J Clin Sleep Med. 2008; 4(6):538-542.

33. Steiropoulos P, Papanas N, Nena E, Maltezos E, Bouros D. continuous positive airway pressure treatment in patients with sleep apnea: does it really improve glucose metabolism? Curr Diabetes Rev 2010; 6(3):156-166.

34. Veber OA. Links between diabetes mellitus and sleep disorders: focusing on obstructive sleep apnea. Orv Hetil $2010 ; 151(1): 8-16$.

35. Botros N, Concato J, Mohsenin V, Selim B, Doctor K, Yaggi HK. Obstructive sleep apnea as a risk factor for type 2 diabetes. Am J Med 2009; 122(12):1122-1127.

36. Oktay B, Akbal E, Firat $H$, Ardic S, Kizilgun M. CPAP treatment in the coexistence of obstructive sleep apnea syndrome and metabolic syndrome, results of one year follow up. Acta Clin Belg 2009; 64(4):329-334.

37. Einhorn D, Stewart DA, Erman MK, Gordon N, PhilisTsimikas A, Casal E. Prevalence of sleep apnea in a population of adults with type 2 Diabetes mellitus. Endocrine Practice 2007; 13(4):355-362.

38. Punjabi NM, Sorkin JD, Katzel LI, et al. Sleep-disordered breathing and insulin resistance in middle - aged and overweight men. Am J Respir Crit Care Med 2002 165:677-682.

39. Ip MS, $\operatorname{Lam} B, \mathrm{Ng} M M$, et al. Obstructive sleep apnea is independently associated with insulin resistance. Am J Respir Crit care Med 2002; 165:670-676.

40. American Academic of Sleep Medicine. International Classification of Sleep Diosrders: Diagnosic and Coding manual. $2^{\text {nd }}$ ed. Westchester, IL. American Academy of Sleep Medicine, 2005

41. Spiegel K, Leproult R, L'Hermite-Baleriaux M, Copinschi G, Penev PD and Van Cauter E. Leptin levels are dependent on sleep duration: relationships with sympathovagal balance, carbohydrate regulation, cortisol, and thyrotropin. J Clin Endocrinol Metab 2004; 89:5762-5771.

42. Spath-Schwalbe E, Gofferje M, Kern W, Born J and Fehm $\mathrm{HL}$. Sleep disruption alters nocturnal ACTH and cortisol secretory patterns. Biol Psychiatry. 1991; 29:575-584. 